\title{
Impact of Appropriateness for Empirical Antibiotics in Patients with Sepsis in the Emergency Department
}

\author{
Panithan Puntawang \\ Chiang Mai University \\ Boriboon Chenthanakij \\ Chiang Mai University \\ Theerapon Tangsuwanaruk \\ Chiang Mai University \\ Pavita Laohakul \\ Chiang Mai University \\ Phichayut Phinyo \\ Chiang Mai University \\ Borwon Wittayachamnankul ( $\nabla$ borwon.witt@cmu.ac.th ) \\ Chiang Mai University
}

\section{Research Article}

Keywords: anti-bacterial agents, anti-infective agents, sepsis, mortality, emergency department

Posted Date: February 8th, 2021

DOI: https://doi.org/10.21203/rs.3.rs-147703/v1

License: (c) (7) This work is licensed under a Creative Commons Attribution 4.0 International License. Read Full License 


\section{Abstract}

\section{Background}

Sepsis drives a worldwide impact on the health care system. The primary problem in treating sepsis is the emergence of multi-drug resistant microbials caused by the improper use of antibiotics. The mortality associated with the improper use of empirical antibiotics consequently adds a burden on the health care system.

\section{Objectives}

To investigate the clinical impact of appropriate empirical antibiotics in sepsis patients who visited the emergency department.

\section{Methods}

A retrospective cohort study was performed on sepsis patients receiving empirical antibiotics in the emergency department. The patients were grouped by laboratory culture results and appropriate use of empirical antibiotics. The impact of empirical antibiotic use such as 30-day mortality, length of hospital stays, length of ICU stays, cost of admission, were analyzed and survival analysis was assessed.

\section{Results}

Appropriate empirical antibiotic use in culture-negative sepsis groups significantly decreased 30-day mortality (Risk ratio $(\mathrm{RR})=0.26,95 \%$ confidence interval $(\mathrm{Cl})=0.15,0.46, \mathrm{P}<0.01)$. While appropriate empirical antibiotic use in culture-positive sepsis groups did not significantly decrease mortality (RR $0.88 ; 95 \% \mathrm{Cl} 0.74,1.05, \mathrm{P}=0.08)$. The length of hospital stays for inappropriate use of empirical antibiotic culture-negative groups were significantly longer, but not significant in the culture-positive group. The length of ICU stays and cost of admission in both groups were not found to be statistically significant.

\section{Conclusions}

Appropriate use of empirical antibiotics in patients with sepsis in culture-negative groups can significantly decrease the 30-day mortality. But in a culture-positive group, the appropriate use of an empirical antibiotic cannot significantly decrease mortality.

\section{Backgrounds}

Sepsis is a life-threatening organ dysfunction caused by an abnormal response precipitated by an infection (1). Sepsis drives a worldwide impact on the health care system with the overall incidence of sepsis worldwide affecting approximately 31.5 million people a year. While the mortality remains high at approximately 5.3 million people per year ${ }^{(2)}$, the empowerment for sepsis treatments is still needed. The primary concern for the management of sepsis in recent years is the emergence of multi-drug resistant microbes, an issue stemming from the improper use of antibiotics $(3,4)$. A recent study shows mortality at a three-fold increase with the improper use of empirical antibiotics in sepsis patients, especially those in septic shock ${ }^{(5)}$. The use of empirical antibiotics in patients with sepsis in the emergency department (ED) does not cover with the causing microbial in 10 to 40 percent. When compared with using empirical antibiotics properly, improper use increased mortality at 16.3 percent while the former was only at 7.0 percent ${ }^{(6)}$.

According to the Surviving Sepsis Campaign 2016 and 2018 updates, the use of appropriate empirical antibiotics in patients with sepsis is mandatory ${ }^{(7,8)}$. The concept of broad-spectrum antibiotics ${ }^{(9-12)}$ and the concept of early combination antibiotic therapy ${ }^{(13,14)}$ was adopted thereafter. This resulted in the overuse of antibiotics ${ }^{(15,16)}$ and the issue with multi-drug resistant microbials started to become more apparent. The colonization of the multi-drug resistant microbial affected treatment with increasing lengths of hospital admissions, cost of hospitalization, and mortality rates ${ }^{(17)}$.

The proper use of empirical antibiotics is regularly assessed using laboratory culture results and the antibiotic susceptibility test for each isolated microbial $\left.{ }^{6}, 10,18\right)$. This assessment causes the limitation to access the proper use in the culture-negative sepsis patients which accounted for 30 to 54 percent of patients with sepsis $(9,19,20)$. Culture-negative cases associated with high mortality were reported ${ }^{(21)}$. Because there is no reference standard to assess proper use and the response of treatment practically using reduction of fever at 72 hours is still controversial. The number of studies assessing the impact of empirical antibiotic treatment in patients with culture-negative sepsis is limited. It is expected that the appropriate use of empirical antibiotics in patients with culture-positive and culture-negative sepsis should reduce mortality, decrease the length of hospital stay, and decrease the cost of hospital admissions. This study to investigate the clinical impact of appropriate empirical antibiotics in patients with sepsis visited the ED. The clinical impact included 30-day mortality, lengths of hospital stays, lengths of ICU stay, and total cost of hospital admission.

\section{Methods}


A retrospective cohort study was performed in the ED of Chiang Mai University Hospital, Thailand from November 2017 to December 2018 . Chiang Mai University Hospital is a tertiary-care, non-profit, university hospital. The estimated number of patients receiving healthcare service is 70,000 patients per month. Of these, roughly 40 patients with sepsis receive care in the ED per month. Inclusion criteria were patients aged older than eighteen years old diagnosed with sepsis by the Third International Consensus definition for sepsis (Sepsis-3) and received at least one dose of the single antimicrobial agent in an ED. The exclusion criteria were patients referred from another hospital with prior intravenous antibiotic exposure, and patients admitted at another hospital where the treatment chart or electronic record database cannot be reviewed to assess treatment outcomes.

The patients were recruited using the ICD-10 referred for sepsis (include A41, R65, R57) from the hospital electronic medical records (EMR; provided by Digicard $2007 \AA$ and $S M I \circledR)$. The chart review was performed by data collectors, consisting of health care providers and technicians. We reassessed the SOFA scores of all patients from the pooled data, included baseline SOFA scores before the current visit and current SOFA scores at emergency room disposition. All intravenous antibiotics given to these patients were counted as empirical antibiotics. If no intravenous antibiotics were given in an ED, these patients were excluded from the study. The patients were identified as an immunocompromised host with at least one of the following conditions: (1) immunosuppression (defined as viral immunosuppression, neoplastic disease, immunosuppressive drugs including steroids, chemotherapy, or congenital immunosuppression), (2) active hematologic malignancy (i.e., still requiring treatment), and (3) active neoplasm (i.e., a neoplasm that has not been resected, still requires treatment, or with metastasis) ${ }^{(22,23)}$. Probe thermometers were used to evaluate body temperature; the probes were placed in the armpit as the most convenient site. The relationship between axillary and core temperature measurement was a moderate to high correlation $(r=0.53-0.90)^{(24-26)}$. The temperature was recorded in Celsius degree units.

Patients were divided into two groups according to laboratory culture information: the culture-positive sepsis (CPS) group and the culture-negative sepsis (CNS) group. All patients were assessed for the appropriateness of empirical antibiotic use (EAU) by pre-defined criteria before the clinical outcomes were assessed. Antibiotic use in compliance with the hospital's Clinical Practice Guidelines (CPG) was also assessed. Patients included in our study were almost treated in compliance with the hospital sepsis practice guideline, developed from the recent updates in Survival Sepsis Campaign - intravenous antibiotic was given within one hour, adequate intravenous fluids were given, and vasopressor was given as indicated. The hemocultures and cultures from source-specific sites were collected by registered nurses to ensure the adequacy of culture results.

Appropriate antibiotic use in the CPS group was judged based on the antibiotic sensitivity data on bacteria isolated from suspected sites of infection. The empirical antibiotic was considered to be appropriate if it covered all causative bacteria. For the culture-negative sepsis group (CNS group), the appropriateness was judged by response to antibiotic treatment, defined as highest body temperature less than 38 degrees Celsius or white blood count less than 10,000 cells per $\mathrm{mm}^{3}$ after treatment ${ }^{(27)}$. The empirical antibiotic was considered to be appropriate if the patient became responsive to treatment at 48-72 hours. All appropriateness of empirical antibiotic use was assessed by the project leader. The overuse of empirical antibiotics was also assessed. The EAU defined as overuse if using the broad-spectrum antibiotic without indications of the hospital's CPG.

The treatment outcomes included 30-day mortality, length of hospital stays, length of ICU stays, and total cost of hospital admission. These outcomes were collected using the data recorded in the EMR. The survival analysis was done in both the CPS and CNS group. Time origin was the day of each hospital admission. All-cause mortalities were counted as an event. The hospital discharge for end-of-life care was also counted as an event only if there was no hospital visit after that disposition. Censoring criteria include patient survival to hospital disposition, except for end-oflife care.

The analysis plan according to a previous study ${ }^{(18)}$. The sample size calculation was assessed by in-hospital mortality of culture-positive sepsis patients with an appropriate antibiotic group (24.2\%) compared to an inappropriate antibiotic group (38.8\%), at a ratio of patient 0.37 . To have power at $80 \%$ and a-level at 0.05 , we enrolled 420 culture-positive patients. Among these, defined as 305 appropriate EAU and 115 as inappropriate EAU. The data was collected until culture-positive patients met with the calculated number. Because there was no data about the impact of appropriate empirical antibiotics in culture-negative sepsis patients, the sample size calculation was not done in this patient group.

Study data were collected and managed using REDCap electronic data capture tools hosted at the Faculty of Medicine, Chiang Mai University. REDCap (Research Electronic Data Capture) is a secure, web-based software platform designed to support data capture for research studies ${ }^{(28,29)}$. The REDCap data was limited access for the related users and the user rights were determined as the data collector, outcome accessor, and project manager. The identifier data was removed before exporting from REDCap. Pooled project data in REDCap was deleted at three months after the final analysis. The data were managed and analyzed by Microsoft Excel ${ }^{\circledR}$ 16.29.1 for Mac (License no. 02954-038-529776) and Stata/MP $® 16.0$ for Mac (Serial no. 501609250008)

\section{Statistical Analysis}

Data analysis used descriptive statistics to measure central tendency and variability. We assessed normality by measuring skewness and kurtosis, histogram, and Kolmogorov-Smirnov tests. The normally distributed numerical variables were presented as mean \pm SD, and other numerical variables as median (interquartile range). Comparison between the study groups was performed; Chi-square and Fisher's exact test were used for 
categorical data. Unpaired t-test, ANOVA, Wilcoxon Rank Sum Test, and Kruskal-Wallis test were used for continuous data. The risk ratio was used to measure 30-day mortality between appropriate and inappropriate EAU group. The survival analysis was performed as a univariate analysis using the log-rank statistic, Kaplan-Meier estimate graph, and Cox analysis model.

\section{Results}

\section{Demographic Data}

The 745 patients were recruited from hospital EMR while 484 patients met the diagnostic criteria for sepsis. 12 patients were excluded; 11 for no intravenous EAU in the ED, and one for a referral to admit in another hospital. 472 patients were included in the review, with 241 culture-positive sepsis (CPS) and 238 culture-negative sepsis (CNS) patients (Fig. 1). The overall survival to hospital discharge was $72.7 \%$. Overall 30-day mortality was $25.4 \%$. The demographic and clinical characteristics of sepsis patients were shown in Table 1. In comparing the CPS and CNS groups, the difference of mean age, status bedridden, and source of infection were statistically significant, but not significant in the subgroup by appropriate empirical antibiotic use (EAU). The leading source of infection was in the respiratory system (36.6\%), followed by the genitourinary system (22.2\%), and gastrointestinal system (14.8\%). Empirical intravenous antibiotic use was following the hospital's clinical practice guidelines (CPG) in $82.5 \%$ of patients, without statistically significant differences between the CPS and CNS groups. In $6.0 \%$ overall, the antibiotic uses were defined as overcoverage. Fifty-six (11.8\%) of all patients could not be evaluated with CPG due to an unknown source of infection. The 128 (27.1\%) of all patients were admitted to a critical care unit. 
Table 1

Demographic data of the recruited patients

\begin{tabular}{|c|c|c|c|c|c|c|c|c|c|c|}
\hline & \multicolumn{4}{|c|}{ Overall $(n=472)$} & \multicolumn{3}{|c|}{ Culture-positive sepsis $(n=234)$} & \multicolumn{3}{|c|}{ Culture-negative sepsis $(n=238)$} \\
\hline & Overall & $\begin{array}{l}\text { CPS } \\
(234)\end{array}$ & $\begin{array}{l}\text { CNS } \\
(238)\end{array}$ & $\begin{array}{l}\text { P- } \\
\text { value* }\end{array}$ & $\begin{array}{l}\text { Appropriate } \\
\text { EAU (179) }\end{array}$ & $\begin{array}{l}\text { Inappropriate } \\
\text { EAU (55) }\end{array}$ & $\begin{array}{l}\mathrm{P} \text { - } \\
\text { value }\end{array}$ & $\begin{array}{l}\text { Appropriate } \\
\text { EAU (129) }\end{array}$ & $\begin{array}{l}\text { Inappropriate } \\
\text { EAU (109) }\end{array}$ & $\begin{array}{l}P \text { - } \\
\text { value }\end{array}$ \\
\hline Age - years & $\begin{array}{l}65.6 \pm \\
17.6\end{array}$ & $\begin{array}{l}68.5 \\
\pm \\
16.8\end{array}$ & $\begin{array}{l}63.5 \pm \\
17.7\end{array}$ & $<0.01$ & $68.8 \pm 17.2$ & $67.2 \pm 15.8$ & 0.54 & $65.1 \pm 17.2$ & $61.7 \pm 18.2$ & 0.15 \\
\hline Male sex - no. (\%) & $\begin{array}{l}257 \\
(54.5)\end{array}$ & $\begin{array}{l}132 \\
(56.4)\end{array}$ & $\begin{array}{l}126 \\
(52.7)\end{array}$ & 0.4 & $101(56.4)$ & $31(56.4)$ & 0.99 & $60(46.5)$ & $69(53.5)$ & 0.43 \\
\hline $\begin{array}{l}\text { Median of increment } \\
\text { SOFA score- pt (IQR) }\end{array}$ & $\begin{array}{l}5(3- \\
7)\end{array}$ & $\begin{array}{l}5(3- \\
7)\end{array}$ & $\begin{array}{l}5(3- \\
7)\end{array}$ & 0.49 & $5(3-7)$ & $5(2-7)$ & 0.75 & $5(3-7)$ & $5(2-7.5)$ & 0.76 \\
\hline $\begin{array}{l}\text { Immunocompromised } \\
\text { host }\end{array}$ & & & & 0.88 & & & 0.79 & & & 0.06 \\
\hline $\begin{array}{l}\text { Immunosuppression } \\
- \text { no. (\%) }\end{array}$ & $\begin{array}{l}21 \\
(4.4)\end{array}$ & $\begin{array}{l}12 \\
(5.1)\end{array}$ & $9(3.8)$ & & $10(5.6)$ & $2(3.6)$ & & $3(2.3)$ & $6(5.5)$ & \\
\hline $\begin{array}{l}\text { Active hematologic } \\
\text { malignancy - no. (\%) }\end{array}$ & $\begin{array}{l}48 \\
(10.4)\end{array}$ & $\begin{array}{l}23 \\
(9.8)\end{array}$ & $\begin{array}{l}25 \\
(10.5)\end{array}$ & & $19(10.6)$ & $4(7.3)$ & & $12(9.3)$ & $13(11.9)$ & \\
\hline $\begin{array}{l}\text { Active neoplasm - } \\
\text { no. (\%) }\end{array}$ & $\begin{array}{l}80 \\
(16.9)\end{array}$ & $\begin{array}{l}40 \\
(17.1)\end{array}$ & $\begin{array}{l}40 \\
(16.8)\end{array}$ & & $31(17.3)$ & $9(16.4)$ & & $16(12.4)$ & $24(22.0)$ & \\
\hline $\begin{array}{l}\text { Status bed ridden - } \\
\text { no. (\%) }\end{array}$ & $\begin{array}{l}67 \\
(14.4)\end{array}$ & $\begin{array}{l}49 \\
(21.3)\end{array}$ & $\begin{array}{l}18 \\
(7.7)\end{array}$ & $<0.01$ & $37(21.1)$ & $12(21.8)$ & 0.92 & $9(7.1)$ & $9(8.3)$ & 0.72 \\
\hline $\begin{array}{l}\text { Prior admission in } 90 \\
\text { days - no. (\%) }\end{array}$ & $\begin{array}{l}170 \\
(52.8)\end{array}$ & $\begin{array}{l}94 \\
(54.0)\end{array}$ & $\begin{array}{l}76 \\
(51.4)\end{array}$ & 0.63 & $71(52.2)$ & $23(60.5)$ & 0.36 & $44(54.3)$ & $32(47.8)$ & 0.42 \\
\hline Source of infection & & & & $<0.01$ & & & 0.26 & & & 0.3 \\
\hline Respiratory - no. (\%) & $\begin{array}{l}173 \\
(36.6)\end{array}$ & $\begin{array}{l}83 \\
(35.5)\end{array}$ & $\begin{array}{l}90 \\
(37.8)\end{array}$ & & $66(36.9)$ & $17(30.9)$ & & $49(40.0)$ & $41(37.6)$ & \\
\hline GU - no. (\%) & $\begin{array}{l}105 \\
(22.2)\end{array}$ & $\begin{array}{l}77 \\
(32.9)\end{array}$ & $\begin{array}{l}27 \\
(11.3)\end{array}$ & & $60(33.5)$ & $17(30.9)$ & & $10(7.8)$ & $17(15.6)$ & \\
\hline GI - no. (\%) & $\begin{array}{l}70 \\
(14.8)\end{array}$ & $\begin{array}{l}25 \\
(10.7)\end{array}$ & $\begin{array}{l}45 \\
(18.9)\end{array}$ & & $15(8.3)$ & $10(18.2)$ & & $26(20.2)$ & $19(17.4)$ & \\
\hline HBP - no. (\%) & $\begin{array}{l}22 \\
(4.7)\end{array}$ & $\begin{array}{l}11 \\
(4.7)\end{array}$ & $\begin{array}{l}11 \\
(4.6)\end{array}$ & & $10(5.6)$ & $1(1.8)$ & & $6(4.7)$ & $5(4.6)$ & \\
\hline CNS - no. (\%) & $\begin{array}{l}11 \\
(2.3)\end{array}$ & $\begin{array}{l}3 \\
(1.3)\end{array}$ & $8(3.4)$ & & $1(0.6)$ & $2(3.6)$ & & $4(3.1)$ & $4(3.7)$ & \\
\hline $\begin{array}{l}\text { Blood stream } \\
\text { infection - no. (\%) }\end{array}$ & $\begin{array}{l}10 \\
(2.1)\end{array}$ & $\begin{array}{l}3 \\
(1.3)\end{array}$ & $7(2.9)$ & & $3(1.7)$ & 0 & & $6(4.7)$ & $1(0.9)$ & \\
\hline $\begin{array}{l}\text { Skin and soft tissue } \\
-- \text { no. (\%) }\end{array}$ & $\begin{array}{l}10 \\
(2.1)\end{array}$ & $\begin{array}{l}7 \\
(3.0)\end{array}$ & $3(1.3)$ & & $5(2.8)$ & $2(3.6)$ & & $1(0.8)$ & $2(1.8)$ & \\
\hline CVS - no. (\%) & $4(0.9)$ & $\begin{array}{l}1 \\
(0.5)\end{array}$ & $3(1.3)$ & & $1(0.6)$ & 0 & & $3(2.3)$ & 0 & \\
\hline Other - no. (\%) & $6(1.3)$ & 0 & $6(2.5)$ & & 0 & 0 & & $2(1.6)$ & $4(3.7)$ & \\
\hline Unidentified - no. (\%) & $\begin{array}{l}62 \\
(13.1)\end{array}$ & $\begin{array}{l}24 \\
(10.3)\end{array}$ & $\begin{array}{l}38 \\
(15.9)\end{array}$ & & $18(10.1)$ & $6(10.9)$ & & $22(17.1)$ & $16(14.7)$ & \\
\hline $\begin{array}{l}\text { Presenting body } \\
\text { temperature - } \\
\text { Celcius }\end{array}$ & $\begin{array}{l}37.7 \pm \\
1.4\end{array}$ & $\begin{array}{l}37.8 \\
\pm 1.4\end{array}$ & $\begin{array}{l}37.6 \pm \\
1.4\end{array}$ & 0.04 & $37.9 \pm 1.4$ & $37.4 \pm 1.3$ & 0.02 & $37.5 \pm 1.3$ & $37.5 \pm 1.5$ & 0.91 \\
\hline $\begin{array}{l}\text { Median of presenting } \\
\text { WBC - } \\
\times 10^{3} / \mathrm{mm}^{3}(\mathrm{IQR})\end{array}$ & $\begin{array}{l}10.1 \\
(5.6- \\
16.3)\end{array}$ & $\begin{array}{l}10.1 \\
(5.3- \\
16.1)\end{array}$ & $\begin{array}{l}10.5 \\
(6.7- \\
16.9)\end{array}$ & & $\begin{array}{l}9.9(5.0- \\
16.1)\end{array}$ & $\begin{array}{l}11.0(5.5- \\
16.1)\end{array}$ & 0.34 & $\begin{array}{l}9.6(6.5- \\
14.6)\end{array}$ & $\begin{array}{l}12.6(7.1- \\
19.0)\end{array}$ & $\begin{array}{l}< \\
0.01\end{array}$ \\
\hline $\begin{array}{l}\text { Median of presenting } \\
\text { neutrophils - \% (IQR) }\end{array}$ & $\begin{array}{l}83.6 \\
(73.6- \\
89.7)\end{array}$ & $\begin{array}{l}84.1 \\
(75.0- \\
90.4)\end{array}$ & $\begin{array}{l}83.0 \\
(72.1- \\
88.4)\end{array}$ & & $\begin{array}{l}84.4(76.0- \\
91.2)\end{array}$ & $\begin{array}{l}83.7(70.9- \\
90.0)\end{array}$ & 0.42 & $\begin{array}{l}81.5(71.2- \\
86.4)\end{array}$ & $\begin{array}{l}85.3(73.8- \\
90.5)\end{array}$ & 0.04 \\
\hline $\begin{array}{l}\text { Disposition to critical } \\
\text { care unit - no. (\%) }\end{array}$ & $\begin{array}{l}128 \\
(27.1)\end{array}$ & $\begin{array}{l}62 \\
(26.5)\end{array}$ & $\begin{array}{l}66 \\
(27.7)\end{array}$ & 0.78 & $48(26.8)$ & $14(25.5)$ & 0.84 & $40(31.0)$ & $26(23.9)$ & 0.22 \\
\hline
\end{tabular}




\begin{tabular}{|c|c|c|c|c|c|c|c|c|c|}
\hline \multirow[b]{2}{*}{$\begin{array}{l}\text { EAU Compliance with } \\
\text { CPG }\end{array}$} & \multicolumn{3}{|c|}{ Overall $(n=472)$} & \multicolumn{3}{|c|}{ Culture-positive sepsis ( $n=234)$} & \multicolumn{3}{|c|}{ Culture-negative sepsis $(n=238)$} \\
\hline & & & & & & & & & 0.85 \\
\hline Compatible - no. (\%) & $\begin{array}{l}343 \\
(82.5)\end{array}$ & $\begin{array}{l}179 \\
(82.1)\end{array}$ & $\begin{array}{l}164 \\
(82.8)\end{array}$ & $148(88.1)$ & $31(62.0)$ & & $89(83.9)$ & $75(81.5)$ & \\
\hline Undercuse - no. (\%) & $\begin{array}{l}48 \\
(11.5)\end{array}$ & $\begin{array}{l}29 \\
(13.3)\end{array}$ & $\begin{array}{l}19 \\
(9.6)\end{array}$ & $12(7.1)$ & $17(34.0)$ & & $10(9.4)$ & $9(9.8)$ & \\
\hline Overuse - no. (\%) & $\begin{array}{l}25 \\
(6.0)\end{array}$ & $\begin{array}{l}10 \\
(4.6)\end{array}$ & $\begin{array}{l}15 \\
(7.6)\end{array}$ & $8(4.8)$ & $2(4.0)$ & & $7(6.6)$ & $8(8.7)$ & \\
\hline \multicolumn{10}{|c|}{$\begin{array}{l}\text { * comparison between culture-positive sepsis group and Culture-negative } \\
\text { sepsis group }\end{array}$} \\
\hline \multicolumn{10}{|c|}{$\begin{array}{l}\text { CNS = central nervous system, CPG = clinical practice guidelines, CVS = cardiovascular system, EAU = Empirical antibiotic use, } \mathrm{HBP}= \\
\text { hepatobiliary system, GI = gastrointestinal system, GU = genitourinary system }\end{array}$} \\
\hline \multicolumn{10}{|c|}{ SOFA score $=$ sequential organ failure assessment score, $\mathrm{WBC}=$ white blood counts } \\
\hline
\end{tabular}

In the CPS group, the mean age was $68.5 \pm 16.8$ years, with $56.4 \%$ male patients. The median of increment SOFA scores in ED was five (3-7), without statistically significant differences between appropriate and inappropriate EAU groups. Seventy-five patients (32.1\%) were defined as immunocompromised host, the etiology of immunocompromise were not statistically different between subgroups. The presenting body temperature was slightly higher in the appropriate EAU group. Moreover, the empirical antibiotic tends to be compatible with antibiotic guidelines in the EAU group which accounted for $81.8 \%$ of the patients.

In the CNS group, the mean age was $63.5 \pm 17.7$ years, with $52.7 \%$ male patients. The median increment of SOFA scores in ED was 5 (3-7) without statistical significance between the appropriate and inappropriate EAU group. There were 74 immunocompromised patients (31.1\%), with no significant differences between appropriate and inappropriate EAU subgroups. The empirical antibiotic use was compatible with guidelines in 164 patients (82.8\%).

Three hundred and forty-three (82.5\%) patients received compatible empirical antibiotics with CPG. Among them, 25 (6.0\%) were defined as an overuse of empirical antibiotics, with no statistical significance between culture-positive and culture-negative sepsis groups $(P=0.24)$. The overuse in the CPS group was in eight patients (4.8\%) inappropriate EAU and two patients (4.0\%) in inappropriate EAU, there was no significance between groups $(P=0.68)$. The overuse in the CNS group was in seven patients $(6.6 \%)$ inappropriate EAU and eight patients (8.7\%) in inappropriate EAU, there was also no statistical significance between groups $(P=0.57)$.

\section{Impact of Empirical Antibiotic Use}

In the CNS group, the appropriate empirical antibiotic use was represented in $54.2 \%$ of patients (Table 2 ). The 30 -day mortality statistics in the appropriate and inappropriate EAU groups was $7.8 \%$ and $45.9 \%$ respectively (Risk ratio $=0.26 ; 95 \%$ confidence interval $0.15,0.46 ; \mathrm{P}<0.01$ ). The appropriate EAU group had longer survival with a median of days between admission and death by 18 (9-20) days, compared with the inappropriate EAU group by 4 (2-7) days. The length of hospital stays in the appropriate EAU group was longer (Median 9 days) compared with the inappropriate EAU group (Median 6 days). Length of ICU stays, and admission costs were not statistically significant between groups.

Table 2

Impact of empirical antibiotic use in the culture-negative sepsis group

\begin{tabular}{|c|c|c|c|}
\hline & Appropriate EAU $n=129$ & Inappropriate EAU n = 109 & P-value \\
\hline 30-day mortality - no. (\%) & $10(7.8)$ & $50(45.9)$ & $<0.01 *$ \\
\hline Median of days from admission to death - days (IQR) & $18(9-20)$ & $4(2-7)$ & $<0.01 \dagger$ \\
\hline Median length of hospital stays - days (IQR) & $9(5-14)$ & $6(3-13)$ & $<0.01 \dagger$ \\
\hline Median length of ICU stays - days (IQR) & $5(3-9)$ & $5(2-7)$ & $0.67+$ \\
\hline Median of admission cost - Thai baht (IQR) & 68334 (32017-129248) & 74050 (31587-137361) & $0.79+$ \\
\hline \multicolumn{4}{|l|}{ EAU = empirical antibiotic use, $\mathrm{ICU}=$ intensive care unit } \\
\hline \multicolumn{4}{|l|}{ * P-value by chi-square test } \\
\hline † P-value by Wilcoxon rank-sum test & & & \\
\hline
\end{tabular}

In the CPS group, the use of appropriate antibiotics was determined in $76.5 \%$ of patients (Table 3 ). The 30 -day mortality was $22.9 \%$ and $34.6 \%$ in the appropriate and inappropriate EAU group respectively, with no statistical significance (Risk ratio $=0.88 ; 95 \%$ confidence interval $0.74,1.05 ; \mathrm{P}=$ 
0.08). The length of hospital stays in the appropriate EAU group was slightly longer (median = 10 days) compared with the inappropriate EAU group (median = 7 days). The length of ICU stays in the inappropriate EAU group was longer. The cost of admission between the two groups was not statistically significant.

Table 3

Impact of empirical antibiotic use in the culture-positive sepsis group

\begin{tabular}{|c|c|c|c|}
\hline & Appropriate EAU $n=179$ & Inappropriate EAU n = 55 & P-value \\
\hline 30-day mortality - no. (\%) & $41(22.9)$ & $19(34.6)$ & $0.08 *$ \\
\hline Median of days from admission to death - days (IQR) & $7(3-19)$ & $7(1.5-23)$ & $0.81 \dagger$ \\
\hline Median length of hospital stays - days (IQR) & $10(5-18)$ & $8(4-21)$ & $0.48+$ \\
\hline Median length of ICU stays - days (IQR) & $5(4-11)$ & $7(2-21)$ & $0.85 t$ \\
\hline Median of admission cost - Thai baht (IQR) & $74051(36619-142644)$ & $65782(34760-16685)$ & $0.86 t$ \\
\hline \multicolumn{4}{|l|}{ EAU = empirical antibiotic use, $\mathrm{ICU}=$ intensive care unit } \\
\hline \multicolumn{4}{|l|}{ * P-value by chi-square test } \\
\hline † P-value by Wilcoxon rank-sum test & & & \\
\hline
\end{tabular}

Survival analysis was done inappropriate and inappropriate EAU in CPS and CNS groups. Appropriate EAU in CNS group significantly reduced mortality (Log-rank $\mathrm{P}<0.01$ ); using Cox analysis, hazard ratio $0.14 ; 95 \%$ confidence interval $0.07,0.28$; $P<0.01$ (Fig. 2 ). Meanwhile, there is no benefit of the appropriate EAU in CPS group on mortality (Log-rank P = 0.12); using Cox analysis, hazard ratio 0.66 ; $95 \%$ confidence interval 0.38 , 1.13; $P=0.12$ (Fig. 2).

In comparison between overuse antibiotic and compatible antibiotic with CPG. It was found that the overuse of empirical antibiotics did not decrease the 30-day mortality in the CPS group $(P=1.00)$, a similar result was also observed in the CNS group $(P=0.71)$. The length of hospital stays after the overuse of EAU did not change in both CPS $(P=0.30)$ and CNS group $(P=0.19)$. The length of ICU stays for overuse EAU did not present differences in both the CPS and the CNS group

$(P=0.62$ and 0.98 respectively). The cost of admission after overuse of EAU was not statistically different in both the CPS and CNS groups ( $=$ 0.52 and 0.40 respectively)

\section{Discussions}

Our study shows the appropriate empirical antibiotic use reduces 30-day mortality in culture-negative sepsis patients. As empirical antibiotic use in our study was most appropriate, the mortality was considerably reduced. Since there is limited data for the appropriate antibiotic treatment in CNS patients, our study is the first report about the impact of the empirical antibiotic use assessed by the measurable clinical response outcomes.

Factors influencing the negative culture result included slow-growing or fastidious bacteria, inadequate sampling, and poor transport conditions (20, 30).

Since a prior study assessed the appropriateness for empirical antibiotics in the CNS group with accepted international norms ${ }^{(31)}$, we considered another criterion to assess clinical response to antibiotic use. We applied a criterion used by another study to the assessed infectious parameter in evaluating resolution of infection in patients diagnosed with pneumonia, using body temperature less than $38.0^{\circ} \mathrm{C}$ or white blood count less than 10,000 cells per $\mathrm{mm}^{3}{ }^{(27)}$. This criteria application is challenging to assess clinical response in our study but reveals interesting outcomes. There are also reports of using clinical pulmonary infection scores (CPIS), inwhich the parameters included evaluation of body temperature and leukocyte count, to guide duration of antibiotic therapy in patients with pneumonia ${ }^{(32)}$. Results from our study support assessing clinical response using the same criteria after empirical antibiotic use, especially in the CNS group. If no clinical responses were met at 48-72 hours, changing the spectrum of antibiotics should be considered.

While the clinical presentation is indistinguishable ${ }^{(33)}$, previous literature indicated that the CPS group is associated with more severity ${ }^{(20)}$. There are reports of appropriate empirical antibiotic use in the CPS group that it is beneficial in decreasing the risk of mortality $(6,18,34)$ with the number needed to treat of $4^{(35)}$. Although the use of appropriate empirical antibiotics in the CPS group is higher than the CNS group, our study found the benefit of appropriate antibiotics on 30-day mortality is inconclusive.

Since there is limited data to support the use of broad-spectrum antibiotics in sepsis care, the broad-spectrum antibiotic should not be used as routine care for the patient with sepsis. There is also limited data assessing the effect of overuse of empirical antibiotics. The overuse of antibiotics in our study shows no reduction in mortality, no decrease in the length of hospital stays, and the cost of admission. Knowledge augmentation in empirical antibiotic use proved to improve the performance in selecting appropriate empirical antibiotics ${ }^{(36)}$, e.g. increasing 
appropriateness of antibiotic use, reduction of the antibiotic spectrum, and decreasing mortality in less than 72 hours. We recommend the use of appropriate antibiotics with the appropriate spectrum to improve outcomes in sepsis care. We did not assess the rate of drug resistance after the overuse of antibiotics, further study should be performed to assess the hazards of overuse.

The treatment outcomes in patients with sepsis in our study are equal to the treatment in a developed country. Since the in-hospital mortality by our study was $27.3 \%$ overall, equal to in-hospital mortality for sepsis in the USA and UK were reported about $28-41 \%$ (37-40). Our quality of care in sepsis met the international standards. There has been limited research on appropriate EAU in sepsis patients diagnosed using the sepsis-3 criteria internationally. Therefore, by recruiting sepsis patients diagnosed with recently revised sepsis-3 criteria ${ }^{(1)}$, we filled this existing research gap.

The main limitation of our study is the small number of patients especially in the CPS group. Although we recruited more patients, the power was still not enough. Further research should recruit more patients to warrant this outcome. Our study did not include some confounding factors such as the lactate clearance, duration of hypotension, and time to the intravenous antibiotic. This could be affecting the mortality of patients with sepsis. The survival analysis in our study utilized an unadjusted hazard ratio. The overuse of antibiotics assessed by our study is based on clinical practice guidelines, not by the culture results and the antibiotic susceptibility test. Further study is advised. This is a preliminary analysis; hence the number of culture-positive sepsis groups could not be achieved by the time of analysis. Further review is currently in progress.

\section{Conclusions}

Appropriate use of empirical antibiotics in patients with sepsis in the culture-negative group can significantly decrease 30-day mortality. But in the culture-positive group, the appropriate use of an empirical antibiotic cannot significantly decrease mortality.

\section{Declarations}

\section{Ethics Approval and Consent to Participate}

The protocol was approved by The Research Ethics Committee, Faculty of Medicine, Chiang Mai University and the informed consent were waived by exemption review (Permission no. EME-2561-05948). The ethical committee allow to access patient data with anonymous before use for research purpose. All methods were performed in accordance with the relevant guidelines and regulations of Declaration of Helsinki.

\section{Consent for publication}

Not applicable.

\section{Competing interests}

The authors declare that they have no competing interests.

\section{Availability of data and materials}

The datasets used and/or analyzed during the current study available from the corresponding author on reasonable request.

\section{Funding}

This work is supported by the Faculty of Medicine, Chiang Mai University, grant number 155-2562.

\section{Acknowledgements}

We would like to thank everyone who participated in sepsis care in emergency department, Maharaj Nakorn Chiang Mai Hospital.

\section{Author information}

Department of Emergency Medicine, Faculty of Medicine, Chiang Mai University, Chiang Mai 50200, Thailand

Panithan Puntawang, Boriboon Chenthanakij, Theerapon Tangsuwanaruk, Pavita Laohakul, Borwon Wittayachamnankul 


\section{Contributions}

PPun.: Conceptualization, Data curation, Formal analysis, Investigation, Visualization; Roles/Writing - original draft; Writing - review \& editing, BC: Roles/Writing - original draft, TT: Data curation, Formal analysis, Software, PL: original draft, review \& editing, PPin.: Formal analysis, BW: Conceptualization, Funding acquisition, Investigation, Project administration, Supervision, Validation, original draft, review \& editing

\section{References}

1. Singer M, Deutschman CS, Seymour CW, Shankar-Hari M, Annane D, Bauer M, et al.The Third International Consensus Definitions for Sepsis and Septic Shock (Sepsis-3).JAMA.2016 Feb 23;315(8):801-10.

2. Fleischmann C, Scherag A, Adhikari NKJ, Hartog CS, Tsaganos T, Schlattmann P, et al.Assessment of Global Incidence and Mortality of Hospital-treated Sepsis.Current Estimates and Limitations.Am J Respir Crit Care Med.2016 Feb 1;193(3):259-72.

3. Ventola CL.The Antibiotic Resistance Crisis.P T.2015 May;40(5):344-52.

4. Huttner A, Harbarth S, Carlet J, Cosgrove S, Goossens H, Holmes A, et al.Antimicrobial resistance: a global view from the 2013 World Healthcare-Associated Infections Forum. Antimicrobial Resistance and Infection Control.2013 Nov 18;2(1):31.

5. Zilberberg MD, Shorr AF, Micek ST, Vazquez-Guillamet C, Kollef MH.Multi-drug resistance, inappropriate initial antibiotic therapy and mortality in Gram-negative severe sepsis and septic shock:a retrospective cohort study.Critical Care.2014 Nov 21;18(6):596.

6. Lee C-C, Lee C-H, Chuang M-C, Hong M-Y, Hsu H-C, Ko W-C.Impact of inappropriate empirical antibiotic therapy on outcome of bacteremic adults visiting the ED.Am J Emerg Med.2012 Oct;30(8):1447-56.

7. Rhodes A, Evans LE, Alhazzani W, Levy MM, Antonelli M, Ferrer R, et al.Surviving Sepsis Campaign: International Guidelines for Management of Sepsis and Septic Shock: 2016.Intensive Care Med.2017 Mar;43(3):304-77.

8. Levy MM, Evans LE, Rhodes A.The Surviving Sepsis Campaign Bundle: 2018 update.Intensive Care Med.2018;44(6):925-8.

9. Flaherty SK, Weber RL, Chase M, Dugas AF, Graver AM, Salciccioli JD, et al.Septic shock and adequacy of early empiric antibiotics in the emergency department.J Emerg Med.2014 Nov;47(5):601-7.

10. Allison MG, Heil EL, Hayes BD.Appropriate Antibiotic Therapy.Emerg Med Clin North Am.2017 Feb;35(1):25-42.

11. Liang SY, Kumar A.Empiric Antimicrobial Therapy in Severe Sepsis and Septic Shock: Optimizing Pathogen Clearance.Curr Infect Dis Rep.2015 Jul;17(7):493.

12. Buckman SA, Turnbull IR, Mazuski JE.Empiric Antibiotics for Sepsis. Surg Infect (Larchmt).2018 Mar;19(2):147-54.

13. Kumar A, Zarychanski R, Light B, Parrillo J, Maki D, Simon D, et al.Early combination antibiotic therapy yields improved survival compared with monotherapy in septic shock: a propensity-matched analysis.Crit Care Med.2010 Sep;38(9):1773-85.

14. Díaz-Martín A, Martínez-González ML, Ferrer R, Ortiz-Leyba C, Piacentini E, Lopez-Pueyo MJ, et al.Antibiotic prescription patterns in the empiric therapy of severe sepsis: combination of antimicrobials with different mechanisms of action reduces mortality.Crit Care.2012;16(6):R223.

15. Karam G, Chastre J, Wilcox MH, Vincent J-L.Antibiotic strategies in the era of multidrug resistance.Crit Care [Internet].2016 [cited 2018 Aug 20];20.Available from:https://www.ncbi.nlm.nih.gov/pmc/articles/PMC4916531/

16. Fair RJ, Tor Y.Antibiotics and Bacterial Resistance in the 21st Century.Perspect Medicin Chem. 2014 Aug 28;6:25-64.

17. Tseng W-P, Chen Y-C, Chen S-Y, Chen S-Y, Chang S-C.Risk for subsequent infection and mortality after hospitalization among patients with multidrug-resistant gram-negative bacteria colonization or infection.Antimicrob Resist Infect Control. 2018 Jul 31;7:93-93.

18. Yokota PKO, Marra AR, Martino MDV, Victor ES, Durão MS, Edmond MB, et al.Impact of Appropriate Antimicrobial Therapy for Patients with Severe Sepsis and Septic Shock -A Quality Improvement Study.PLoS One [Internet].2014 Nov 6 [cited 2018 Aug 22];9(11).Available from:https://www.ncbi.nlm.nih.gov/pmc/articles/PMC4222820/

19. Kethireddy S, Bilgili B, Sees A, Kirchner HL, Ofoma UR, Light RB, et al.Culture-Negative Septic Shock Compared With Culture-Positive Septic Shock: A Retrospective Cohort Study.Crit Care Med.2018;46(4):506-12.

20. Phua J, Ngerng W, See K, Tay C, Kiong T, Lim H, et al.Characteristics and outcomes of culture-negative versus culture-positive severe sepsis. Crit Care.2013 Sep 12;17(5):R202.

21. Gupta S, Sakhuja A, Kumar G, McGrath E, Nanchal RS, Kashani KB.Culture-Negative Severe Sepsis: Nationwide Trends and Outcomes.Chest.2016 Dec 1;150(6):1251-9.

22. Cortegiani A, Madotto F, Gregoretti C, Bellani G, Laffey JG, Pham T, et al.Immunocompromised patients with acute respiratory distress syndrome:secondary analysis of the LUNG SAFE database.Critical Care.2018 Jun 12;22(1):157.

Page 9/12 
23. Bellani G, Laffey JG, Pham T, Fan E, Brochard L, Esteban A, et al.Epidemiology, Patterns of Care, and Mortality for Patients With Acute Respiratory Distress Syndrome in Intensive Care Units in 50 Countries.JAMA.2016 Feb 23;315(8):788-800.

24. Fulbrook P.Core body temperature measurement:a comparison of axilla, tympanic membrane and pulmonary artery blood temperature.Intensive and Critical Care Nursing.1997 Oct 1;13(5):266-72.

25. Giuffre M, Heidenreich T, Carney-Gersten P, Dorsch JA, Heidenreich E. The relationship between axillary and core body temperature measurements.Applied Nursing Research.1990 May 1;3(2):52-5.

26. Marui S, Misawa A, Tanaka Y, Nagashima K.Assessment of axillary temperature for the evaluation of normal body temperature of healthy young adults at rest in a thermoneutral environment.J Physiol Anthropol.2017 Feb 22;36(1):18-18.

27. Dennesen PJ, van der Ven AJ, Kessels AG, Ramsay G, Bonten MJ.Resolution of infectious parameters after antimicrobial therapy in patients with ventilator-associated pneumonia.Am J Respir Crit Care Med.2001 May;163(6):1371-5.

28. Harris PA, Taylor R, Thielke R, Payne J, Gonzalez N, Conde JG.Research electronic data capture (REDCap)-A metadata-driven methodology and workflow process for providing translational research informatics support.Journal of Biomedical Informatics.2009 Apr 1;42(2):377-81.

29. Harris PA, Taylor R, Minor BL, Elliott V, Fernandez M, O’Neal L, et al.The REDCap consortium: Building an international community of software platform partners.J Biomed Inform.2019 Jul;95:103208.

30. de Prost N, Razazi K, Brun-Buisson C.Unrevealing culture-negative severe sepsis.Crit Care.2013;17(5):1001.

31. Kumar A, Roberts D, Wood KE, Light B, Parrillo JE, Sharma S, et al.Duration of hypotension before initiation of effective antimicrobial therapy is the critical determinant of survival in human septic shock.Crit Care Med.2006 Jun;34(6):1589-96.

32. Jindal SK.Handbook of Pulmonary and Critical Care Medicine [Internet].MCGRAW-HILL EDUCATION; 2019.Available from:https://books.google.co.th/books?id=t3KSDwAAQBAJ

33. Sigakis MJG, Jewell E, Maile MD, Cinti SK, Bateman BT, Engoren M.Culture-Negative and Culture-Positive Sepsis:A Comparison of Characteristics and Outcomes.Anesthesia \& Analgesia [Internet].2019;129(5).Available from:https://journals.Iww.com/anesthesiaanalgesia/Fulltext/2019/11000/Culture_Negative_and_Culture_Positive_Sepsis_A.19.aspx

34. Davey PG, Marwick C.Appropriate vs. inappropriate antimicrobial therapy.Clinical Microbiology and Infection. 2008 Apr 1;14:15-21.

35. Vazquez-Guillamet C, Scolari M, Zilberberg MD, Shorr AF, Micek ST, Kollef M.Using the number needed to treat to assess appropriate antimicrobial therapy as a determinant of outcome in severe sepsis and septic shock.Crit Care Med.2014 Nov;42(11):2342-9.

36. Ferrer R, Martínez ML, Gomà G, Suárez D, Álvarez-Rocha L, de la Torre MV, et al.Improved empirical antibiotic treatment of sepsis after an educational intervention: the ABISS-Edusepsis study.Critical Care.2018 Jun 22;22(1):167.

37. Walkey AJ, Lagu T, Lindenauer PK.Trends in sepsis and infection sources in the United States. A population-based study.Ann Am Thorac Soc.2015 Feb;12(2):216-20.

38. Rhee C, Jones TM, Hamad Y, Pande A, Varon J, O’Brien C, et al.Prevalence, Underlying Causes, and Preventability of Sepsis-Associated Mortality in US Acute Care Hospitals.JAMA Network Open. 2019 Feb 15;2(2):e187571-e187571.

39. Burki TK.Sharp rise in sepsis deaths in the UK.The Lancet Respiratory Medicine.2018 Nov 1;6(11):826.

40. Sprung CL, Annane D, Keh D, Moreno R, Singer M, Freivogel K, et al.Hydrocortisone Therapy for Patients with Septic Shock.N Engl J Med.2008 Jan 10;358(2):111-24.

\section{Figures}




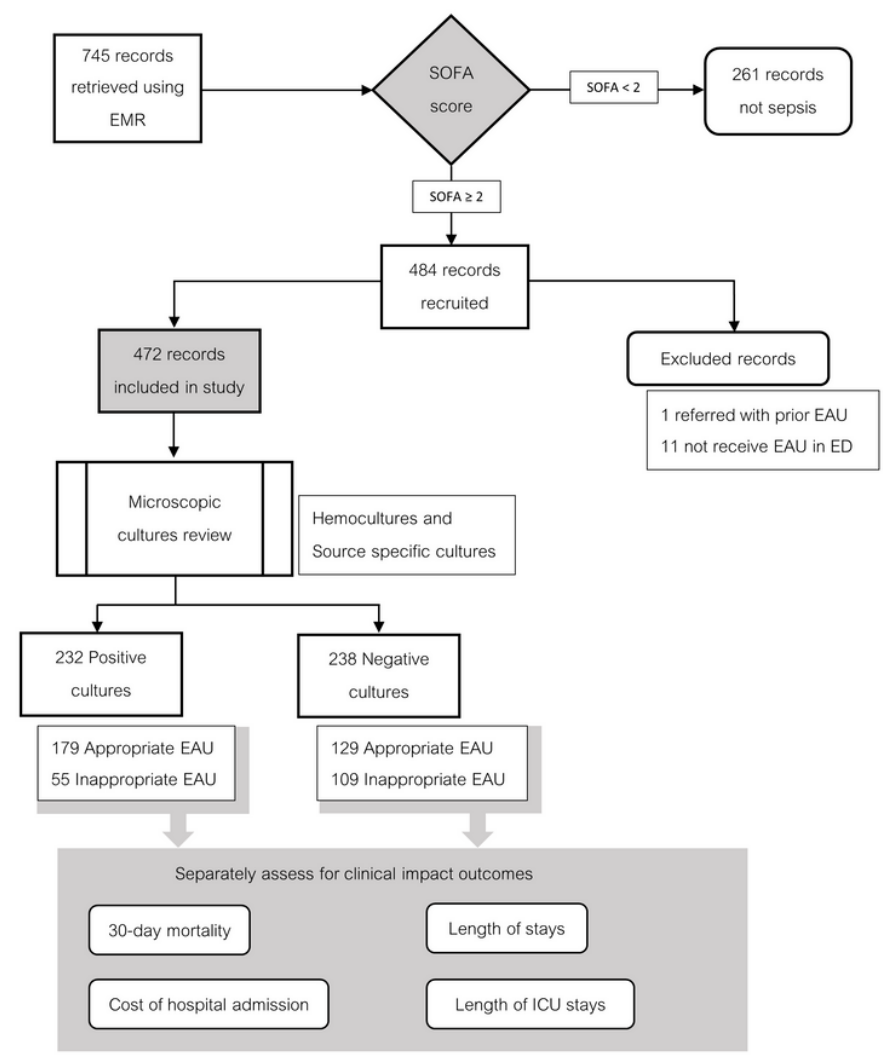

\section{Figure 1}

Research flow chart and methodology process. 

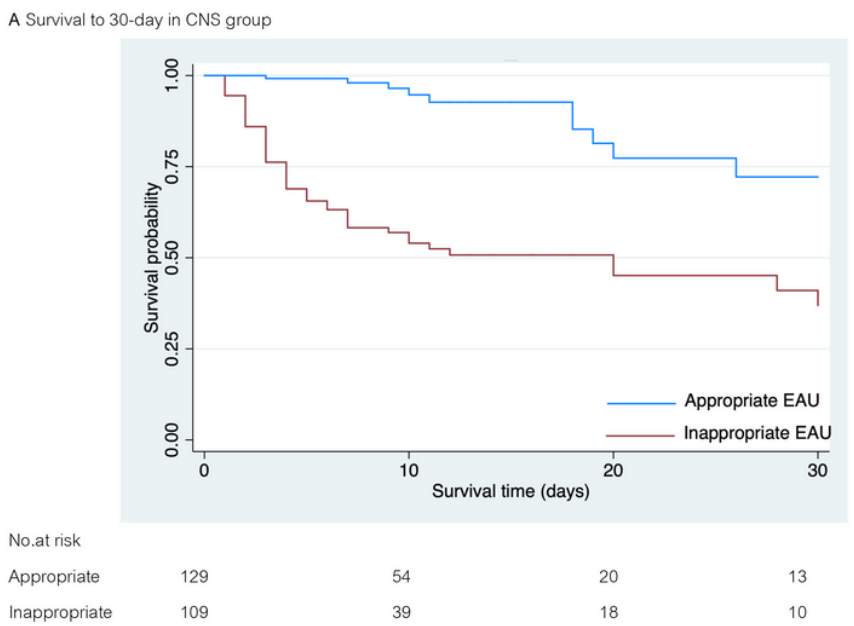

$\begin{array}{lllll}\text { Inappropriate } & 109 & 39 & 18 & 10\end{array}$

B Survival to 30 -day in CPS group

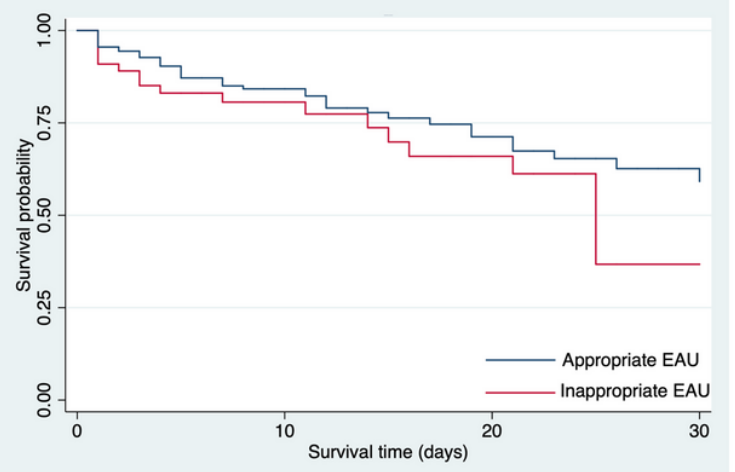

No. at risk

Appropriate

179

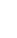

40

Inappropriate

55

93

40

18

$26 \quad 15 \quad 4$

\section{Figure 2}

Kaplan-Meier Curves for survival according to appropriate and inappropriate EAU. A) Culture-negative sepsis. Patients who received appropriate antibiotics had better survival than those who received inappropriate antibiotics $(P<0.01$ by the log-rank test). $B)$ Culture-positive sepsis. There is no difference in mortality between appropriate and inappropriate group $(P=0.12$ by the log-rank test) 